بررسى رفتار هاى پيشگَير انه از بيمارى سالك در شهرستان مهران در سال سوسا:

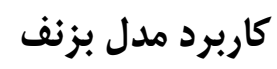

محماباقر جعنريور'، على اشرف عيوضى'، اسداله جلالى '، زينب غضنفرى ‘،*

1) كروه بهداشت عمومى، دانشكده بهداشت، دانشكاه علوم يزشكى إيلام، إيلام، إيران

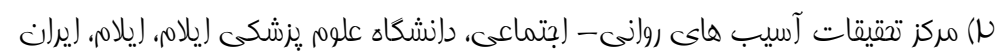

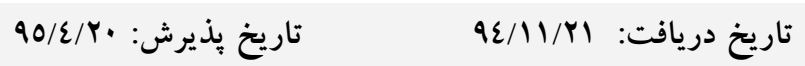

" مقدمه: بيمارى سالك در M كشور جهان آندميك است و •هـ ميليون نفر در جهان در معرض خطر اين بيمارى قرار دارند. اين مطالعه

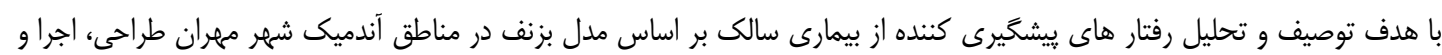
ارزيابى شد.

مواد و روث ها: در اين مطالعه rو نفر از مراجعين بالاى \\ سال ساكن شهرستان به مركز بهداشتى درمانى شماره يك شهر مهران،

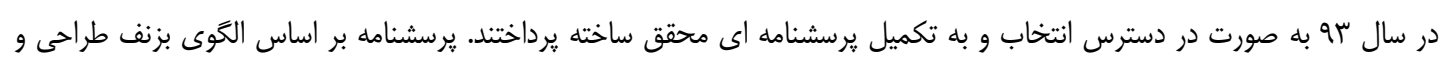

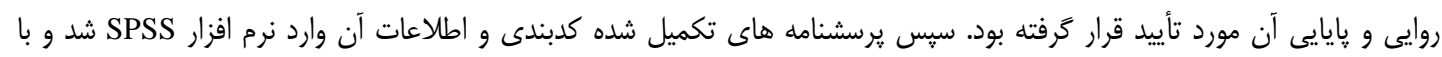

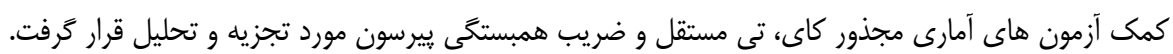

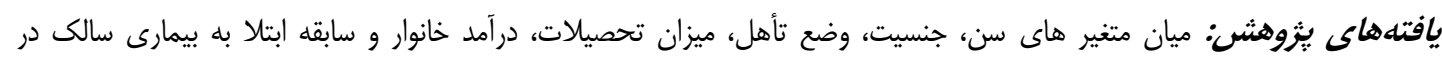

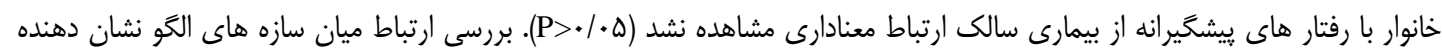

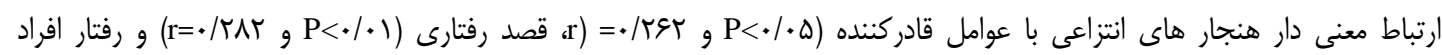

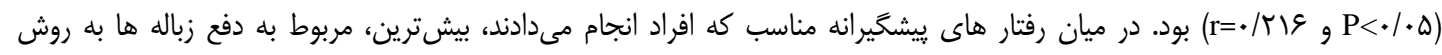

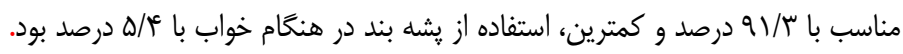

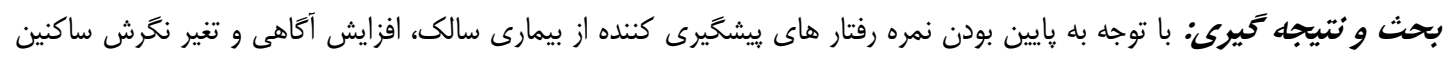

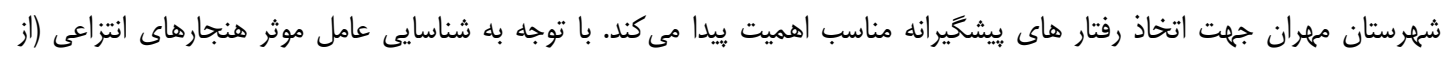

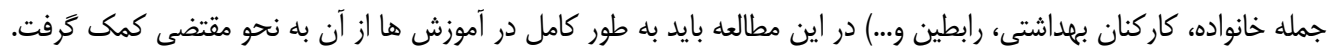

وازه هاى كليدى: سالك، مدل بزنف، رفتار هاى ييشخيرى كننده، آموزش بهداشت

* نويسنده مسئول: گروه بهداشت عمومى، دانشكده بهداشت، دانشگاه علوم يزشكى ايلام، ايلام، ايران

Email: ghazanfari-z@medilam.ac.ir

Copyright (c) 2017 Journal of Ilam University of Medical Science. This is an open-access article distributed under the terms of the Creative Commons Attribution international 4.0 International License (https://creativecommons.org/licenses/by-nc/4.0/) which permits copy and redistribute the material, in any medium or format, provided the original work is properly cited. 
درمان و عوارض ناشى از درمان با دارو هاى موجود،

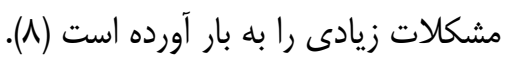

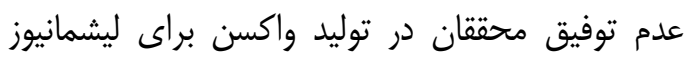

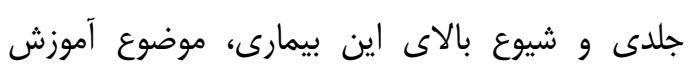

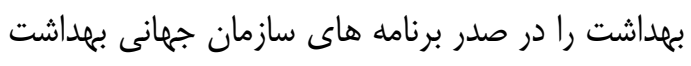

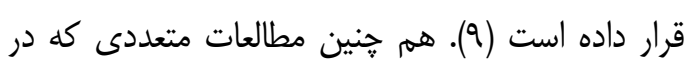

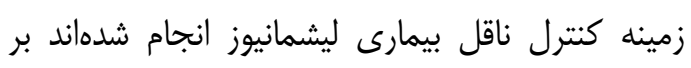

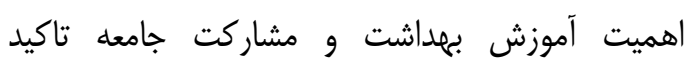
كردهاند (1).(1). براى آموزش مؤثر بايد وضعيت موجود به طور جامع و كامل مورد بررسى قرار گيرد.

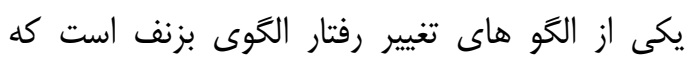
براى مطالعه، شناسايى و تغيير رفتار در جوامع در حال

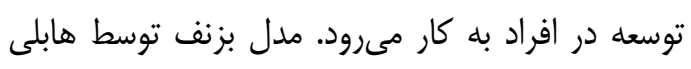

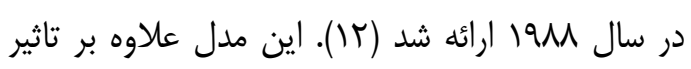

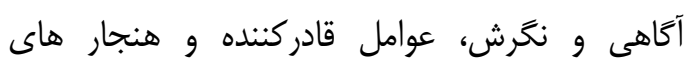

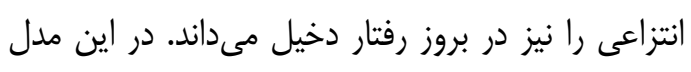

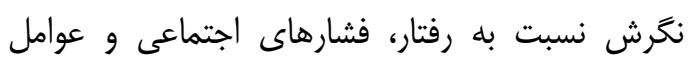

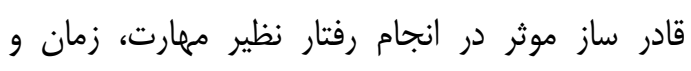
هزينه مورد بررسى قرار مى گيرند (سار).

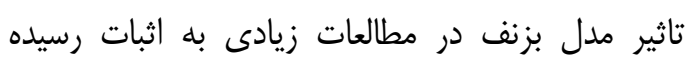
است. نمونه اى از آن ها، مطالعه باقيانى مقدم و ماني

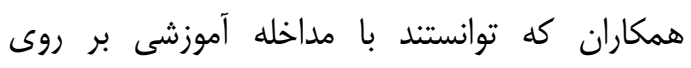

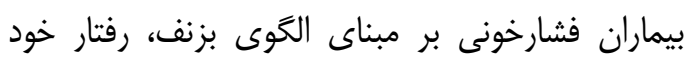

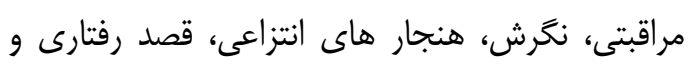

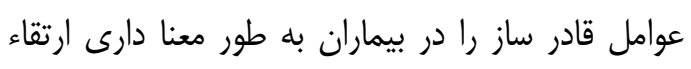

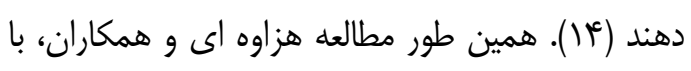

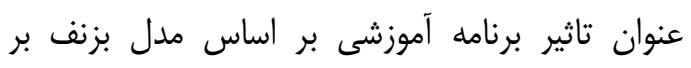

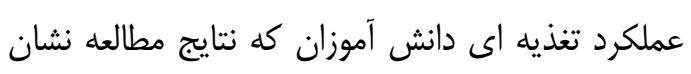

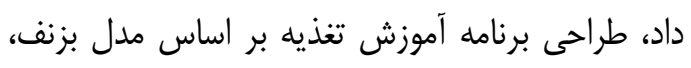

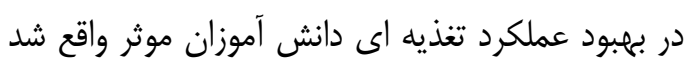

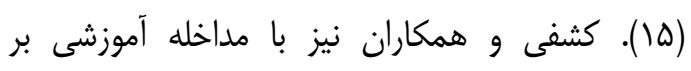

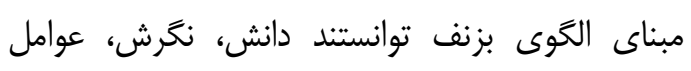

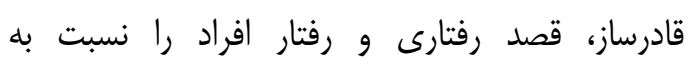
ييشخيرى از بيمارى سالك به طور معنى دارى ارتقاء بخشند (عا). هزاوه اى و همكاران نيز در مطالعه خود

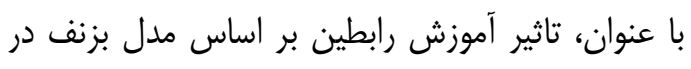

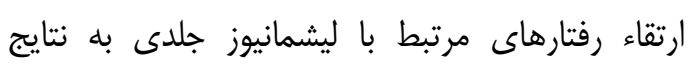

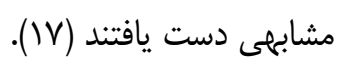

مقدمه: ليشمانيوز (Leishmaniasis) از بيمارى هاى مشترى

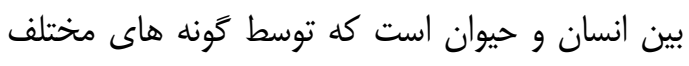

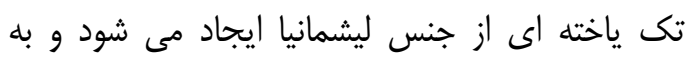

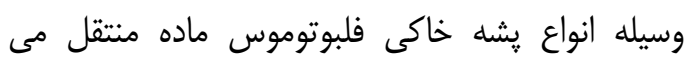
شود. اين بيمارى به سه فرم جلدى (سالك)، احشايى

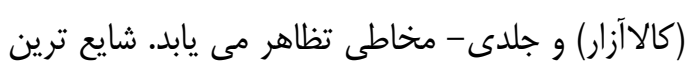

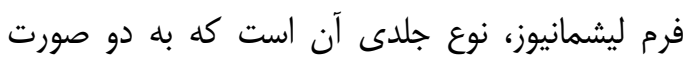
خشى (شهرى) و مرطوب (روستايى) مشاهده مى شود. در اين بيمارى مخازن انكل متفاوت است، به طورى كه

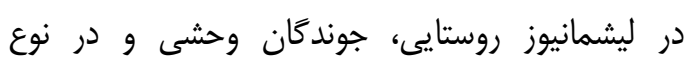
ليشمانيوز شهرى، سخ و كاهى انسان (ميزبان اتفاقى)

به عنوان مخزن انغل محسوب مى شوند (().

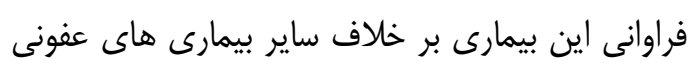

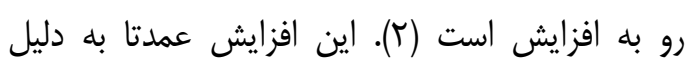
مهاجرت، جابجايى جمعيت، گرمايش جهانى و تغييرات در اكولوزى انسانى است (َّ، أ).

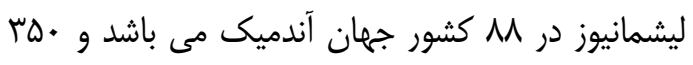
ميليون نفر در جهان در معرض خطر ابتلا هستند.

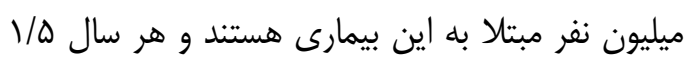

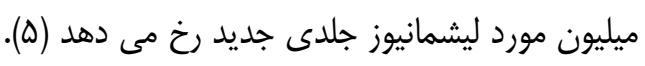

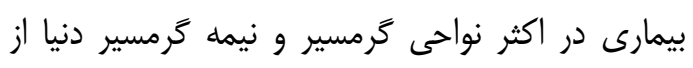
جهار قاره جهان، به عنوان معضل بهرئ دراشتى شناخته

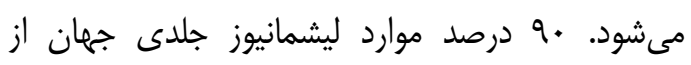

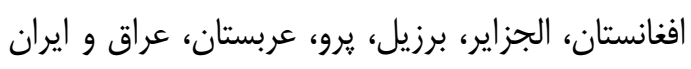

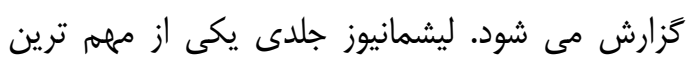
بيمارى هاى بومى ايران و دومين بيمارى انخلى منتقله

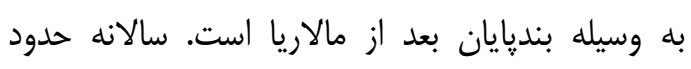

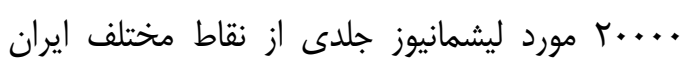
كزارش مى شود كه بايد توجه داشت ميزان واقعى آن آن

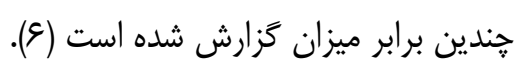

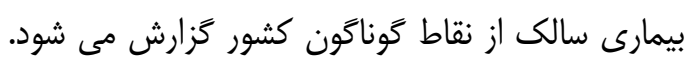

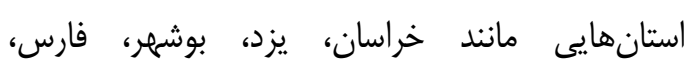

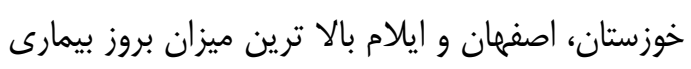

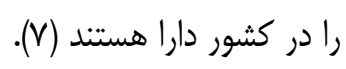
اين بيمارى به دليل طولانى بودن دوره زخهم، ايجاد

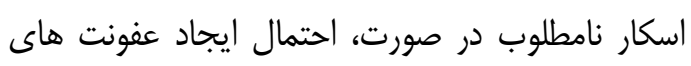
ثانويه، هزينه درمانى سنخين براى جامعله، دوره طولانى إنى 
بيمارى سالك اطلاعات كسب كنم) و بخش ينجم سوالات مربوط به عوامل قادركننده (ها سوال؛ براى بهاى مثال: ا- آيا توان مالى خريد تمادهاى دفع كننده

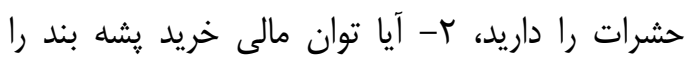
داريد) و بخش ششم به رفتار يا عملكرد افراد در الئ دريل خصوص سالى (V) سوال؛ براى مثال: ا- در هنگام

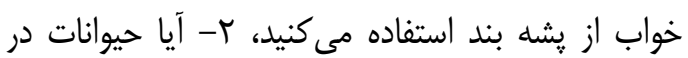
منزل يا مجاورت محل مسكونى نكَهدارى مى كنيد) مىيرداخت. سوالات نخرش بر اساس مقياس رينج كزينه اى ليكرت طراحى شده بودند (كاملا موافقم، موافقم، نه موافقم نه مخالف، مخالفم و كاملا مخالفهم).

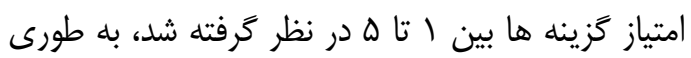

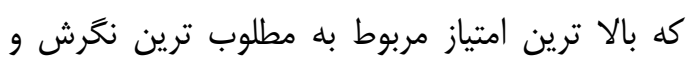
كم ترين امتياز به نا مطلوب ترين نحرش تعلق مى كرفت و كل نمره از هأ تراز شده بود.

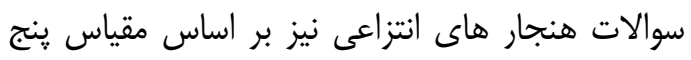

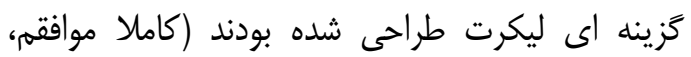
موافقم، نه موافقم نه مخالف، مخالفم و كاملا مخالفم).

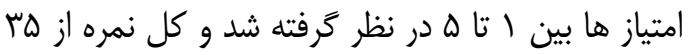
تراز شده بود. سوالات قصد رفتارى نيز مطابق سوالات نخرش ود و هنجار هاى انتزاعى بر اساس مقياس ينج كزينه اى ني ليكرت طراحى شده بودند و كل نمره قصد رفتارى هم

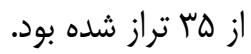

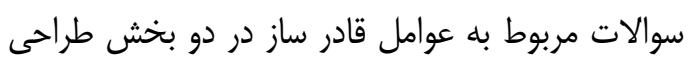
شد. بخش اول سوالات مربوط به سنجش آكًاهى افراد در خصوص ابعاد مختلف بيمارى سالك كه به صورت

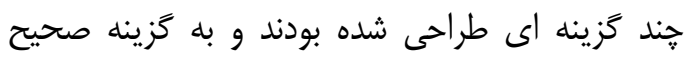

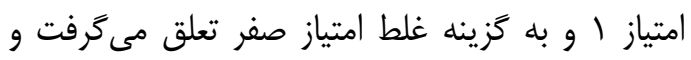
بخش دوم سوالات مربوط به عوامل تسهيل كننده و بازدارنده كه به صورت سه كزينه اى (بلى تا حدى و

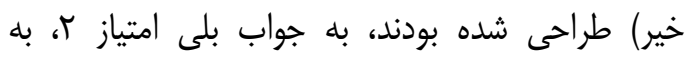

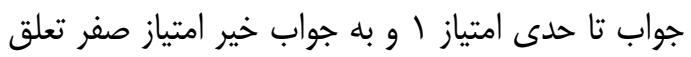

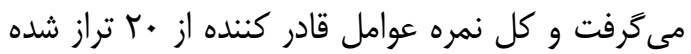

سوالات مربوط به رفتار به دو صورت، دو گزينه اى

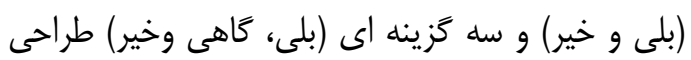

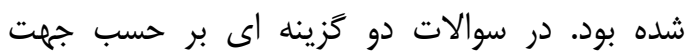

با توجه به كمبود مطالعات تحليلى بر اساس الحَو هاى تغيير رفتار، اين مطالعه با هدف توصيف و تحليل رفتار هاى ييشگيرى كننده از بيمارى سالك بر اساس مدل

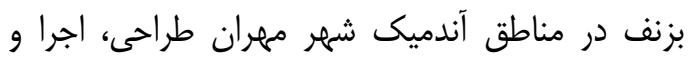

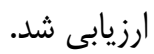

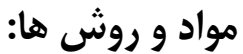

مطالعه حاضر مطالعه اى مقطعى است كه در سال

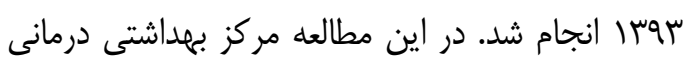
شماره يك واقع در شايع ترين منطقه آندميك بيمارى

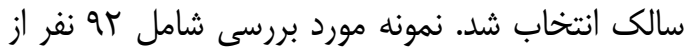
افراد مراجعه كننده به مركز بود كه به روش نمابه نمونه كيرى در دسترس انتخاب شدند. معيار هاى ورود افراد به مطالعه شامل سكونت درن درن شهرستان مهران و حداقل سن \1 ساله بود. هم هنين افراد سالمند و ناتوان به لحاظ جسمى و و ذهنى از

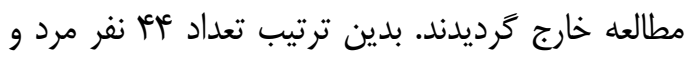

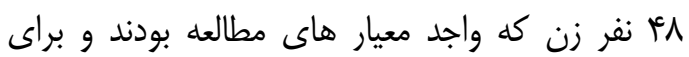
شركت در مطالعه رضايت داشتند، انتخاب شدند.

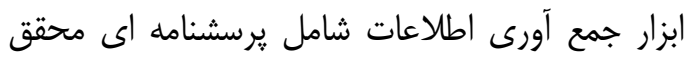

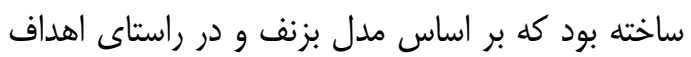

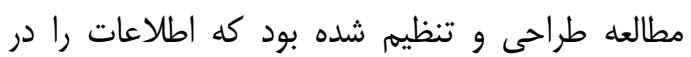
شش بخش جمع آورى مى كرد. بخش اول اطلاعات جمعيت شناختى، بخش دوم سوالات مربوط به سنجش برى

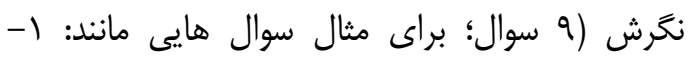

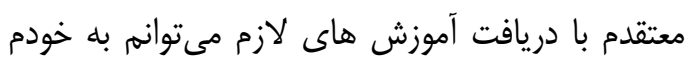
در ييشگيرى از ابتلا به بيمارى سالك كمى كنه، ك-

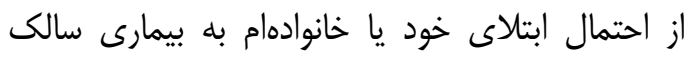

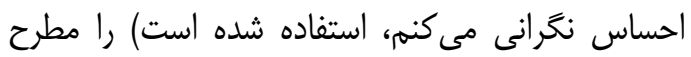

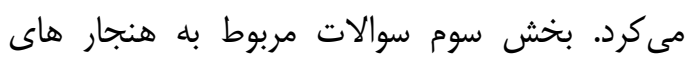

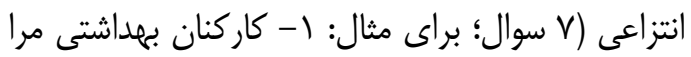
جهت انجام اقدامات ييشخيرى كننده از بيمارى سالى

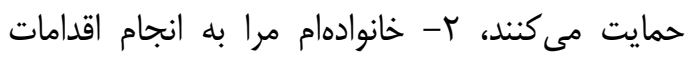
ييشخيرى كننده از بيمارى سالك تشويق مى كنند) بود. بخش جهبارم سوالات مربوط به قصد رفتارى (V سوال؛ براى مثال: ا- مىخواهم در ماه آينده در منزل از از

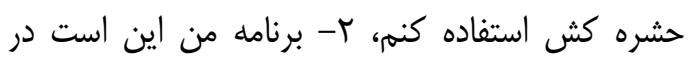

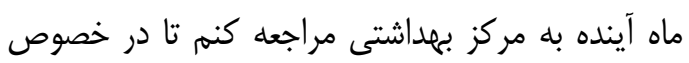


هاى تكميل شده كدبندى و اطلاعات وارد نرم افزار SPSS تى مستقل و ضريب همبستخى ييرسون تجزيه و تحليل شد.

\section{يافته هاى يزوهش:}

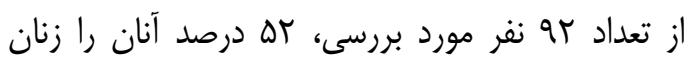

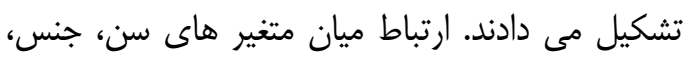
وضع تاهل، ميزان تحصيلات، درآمد خانوار و سابقه

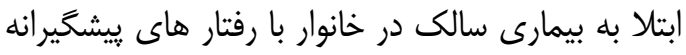
از بيمارى سالك در جدول شماره ا ارائه شده است كه بهاري

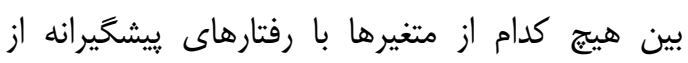
بيمارى ارتباط معنا دارى مشاهده نشد (ه •/ (P>).
سوالات به انجام رفتار مناسب امتياز 1 و عدم انجام

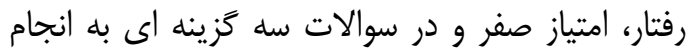
رفتار مناسب امتياز ؟، كاهى امتياز او و عدم انجام رفتار

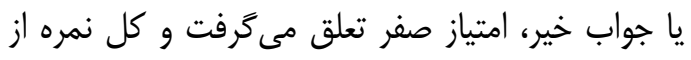

$$
\text { ال ال تراز شده بود. }
$$

روايى يرسشنامه به شيوه روائى محتوى كيفى با

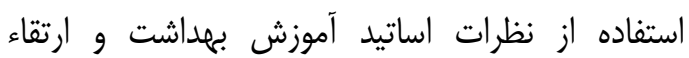

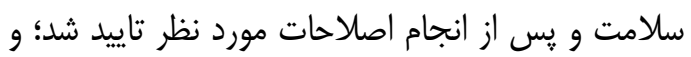

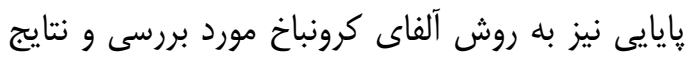

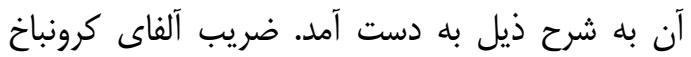
براى كليه سازه هاى مدل به غير از سازه نخرش و

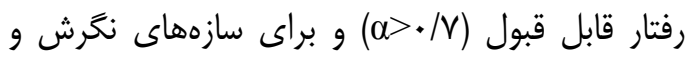

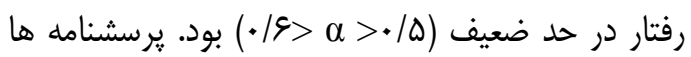
در مركز با حضور محقق تكميل شد، سيس يرسشنامه

جدول ا. مشخصات جمعيت شناختى شركت كنند كان در يزوهش بر حسب رفتار هاى بيشكَيرى كننده از بيمارى سالى

\begin{tabular}{|c|c|c|}
\hline سطح معنى دارى & رفتارهاى بيشكَيرى كننده /ز بيمارى هاى سالى & 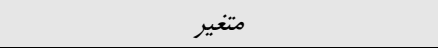 \\
\hline & ميانخين 土|نحراف معيار & \\
\hline & & 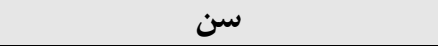 \\
\hline \multirow[t]{3}{*}{$\cdot / r$} & $1 / 99 \pm \varepsilon / \pi r$ & · • س سال و كمتر \\
\hline & $\Delta / 91 \pm 1 / 9$. & بزرگتر از •r سال \\
\hline & & جنسيت \\
\hline \multirow[t]{3}{*}{$\cdot / 4 q$} & $8 / \% \& \pm 1 / 99$ & مرد \\
\hline & $1 / \Delta \xi \pm \Delta / \wedge \mu$ & 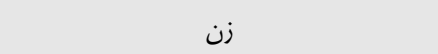 \\
\hline & & وضع تآهل \\
\hline \multirow[t]{3}{*}{.$/ 99$} & $1 / r \pm \Delta / \mathrm{V} \Lambda$ & مجرد \\
\hline & $1 / 9 \Delta \pm \varepsilon / r$ & متأهل \\
\hline & & ميزان تحصيلات \\
\hline \multirow{4}{*}{ מعi } & 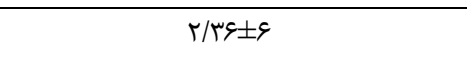 & ابتدائى \\
\hline & $r / \cdot r \pm g / r \Lambda$ & راهنمائى و دبيرستان \\
\hline & $1 / \leftarrow q \pm \Delta / \wedge \Delta$ & دانشخاهى \\
\hline & & 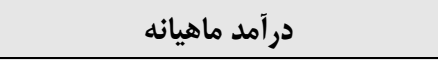 \\
\hline \multirow{4}{*}{$\cdot / \Lambda V$} & $1 / 9 \vee \pm 8 / 11$ & كمتر از ·. هـ هزار تومان \\
\hline & $1 / 8 x \pm \varepsilon / .9$ & 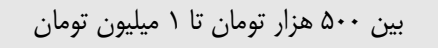 \\
\hline & $1 / V^{\varepsilon} \pm \Delta / 9$ & بيشتر از | ميليون تومان \\
\hline & & ابتلاى ديكر اعضاى خانواده به سالك \\
\hline \multirow[t]{2}{*}{$\cdot / \mathrm{V}$} & $1 / \Delta F \pm \varepsilon / I T$ & بله \\
\hline & $1 / 9 \Delta \pm 9 / .9$ & خير \\
\hline
\end{tabular}

ييشَّيرى از اين بيمارى در جدول شماره r آمده است،

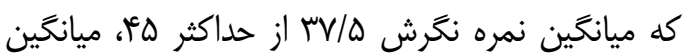

ميانخَين نمرات نخحرش، هنجارهاى انتزاعى، عوامل قادرساز، قصد رفتارى و رفتار افراد در خصوص لفان 


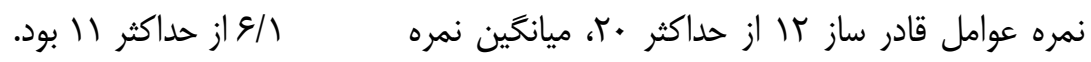

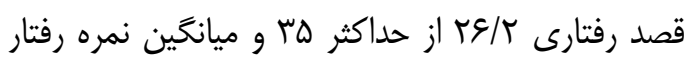

جدول r. ميانكَين و انحراف معيار سازه هاى مدل بزنف

\begin{tabular}{|c|c|c|}
\hline انحراف معيار 土 ميانكين & حداكثر نمره-حداقل نمره & \\
\hline$r V / \Delta \pm \Psi / r$ & ra-ra & نغرش نسبت به رفتار \\
\hline$r \varepsilon / I \pm r / R V$ & טמ & هنجار هاى انتزاعى \\
\hline $\mid r \pm r / 9 \Delta$ & $r-r$. & عوامل قادرساز \\
\hline$r \varepsilon / r \pm F / T$ & 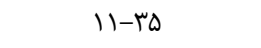 & قصد رفتارى \\
\hline $8 / 1 \pm 1 / v 9$ & $r-11$ & رفتارهاى ييشگيرنده از بيمارى سالى \\
\hline
\end{tabular}

نتايج بررسى ارتباط بين سازه هاى مدل بزنف نشان

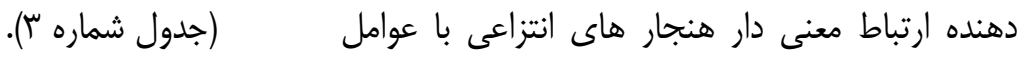

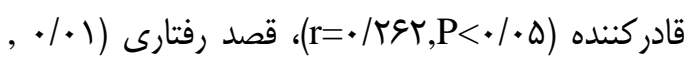

جدول س. ارتباط بين سازههاى مدل بزنف در مطالعه رفتار هاى بيشكَيرى كننده از بيمارى سالك

\begin{tabular}{|c|c|c|c|c|c|}
\hline رفتار & قصد رفتارى & عوامل قادرساز & هنجارهاى انتزاعى & نكرش & \\
\hline & & & & 1 & نغرش \\
\hline & & & 1 & Ar & هنجارهاى انتزاعى \\
\hline & & 1 & "*/rgr & $.1 \cdot+\wedge$ & عوامل قادرساز \\
\hline & 1 & $.1 \cdot 4 \wedge$ & "***..$/ T A T$ & . IIme & قصد رفتارى \\
\hline 1 & $.1 . \mathrm{rq}$ &.$/ N \Delta$ & 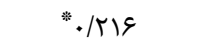 &.$- / \cdot \pi r$ & رفتار \\
\hline
\end{tabular}

سكونت به ميزان \&V/T درصد و نصب تورى ريز در همل اتاق ها به ميزان

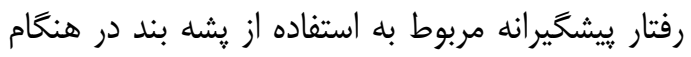

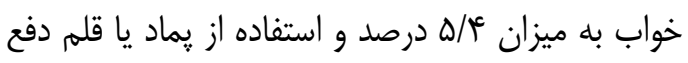
كننده حشرات به ميزان N/V درصد بود. بديهى است

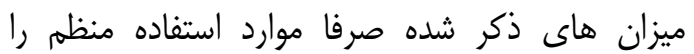
شامل مى شود.
شيوع رفتار هاى ييشگيرى كننده از بيمارى سالى در جمعيت مورد بررسى نيز در جدول شماره أ ارائه شده است كه بيشترين شيوع رفتار بيشگيرانه به ترتيب مربوط به دفع زباله ها به روش صحيح به ميزان سين سئ

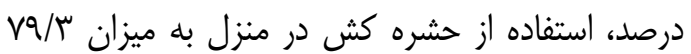

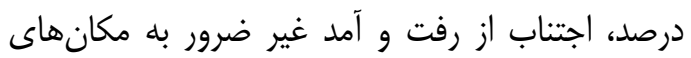

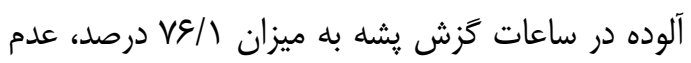

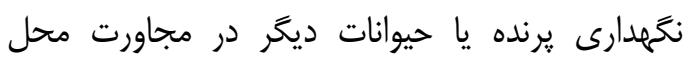


جدول f. فراوانى رفتار هاى بيشگيرى كننده از بيمارى سالك در جمعيت مورد بررسى

\begin{tabular}{|c|c|c|c|c|}
\hline فراوانى (درصد) & فراوانى (درصد) & فراوانى (درصد) & & \\
\hline$(\% \wedge \vee) \wedge$. & $(\% \vee / \&) \vee$ & $(\% \Delta / \uparrow) \Delta$ & استفاده از پشه بند در هنگام خواب & 1 \\
\hline 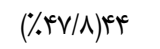 & - & $(\% \Delta T / Y) \leftarrow \Lambda$ & نصب تورى ريز در همه اتاقها جهت جلوكيرى از ورود يشه به خانه و محل استراحت & r \\
\hline$(\% \vee / V) \notin \Delta$ & $(\%+/ V) 19$ & $(\% / \mathrm{V}) \Lambda$ & استفاده از بماد (قلم) دور كننده حشرات & r \\
\hline 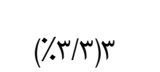 & $(\% \Delta / \uparrow) \Delta$ & $(\% ৭ 1 / r) \wedge \uparrow$ & دفع زبالهها به روش صحيح & r \\
\hline$(\% / \% \cdot / V) 19$ & - & $(\% \vee q / \Gamma) V$ & استفاده از حشره كش در منزل & $\Delta$ \\
\hline & & & اجتناب از رفت و آمد غير ضرور به مكانهاى آلوده در هنكام غروب آفتاب و در طول & \\
\hline$(\% 1 \cdot / 9) 1$. & (4) & $(\% \vee \varepsilon / 1) \vee$. & شنظب منهار از مكان آلوده؛ مكان هاى مخروباه، داراى نخاله ساختمانى و زباله يا اصطبل & 9 \\
\hline 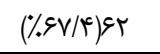 & - & $(\%$ \% $/$ / $/$ r) & نحَهدارى يرنده يا حيوانات در منزل يا مجاور محل مسكونى & $\checkmark$ \\
\hline
\end{tabular}

سالك توسط افراد، كاركنان بهداشتى و افراد درجه يك

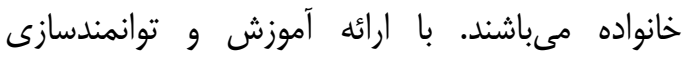

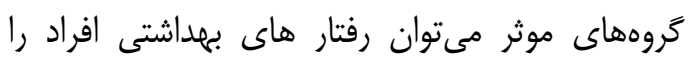

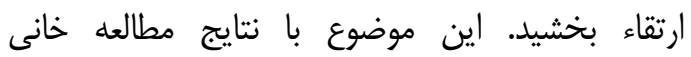

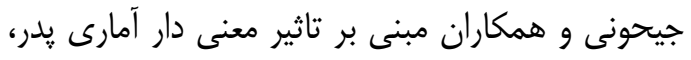

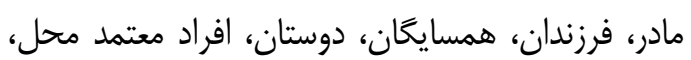

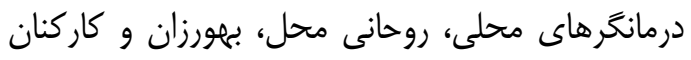
بهداشتى بر خانوارها، هم خوانى دارد (19). بديهى است مانى

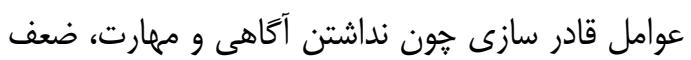

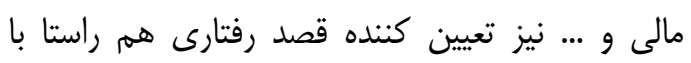

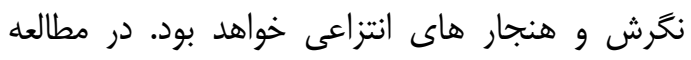

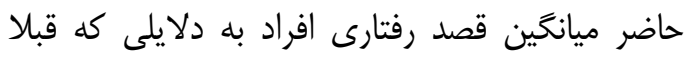

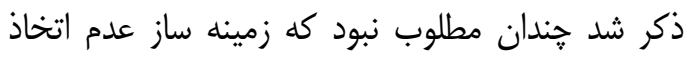

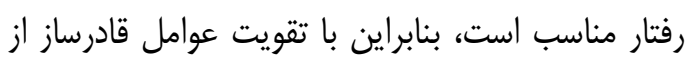

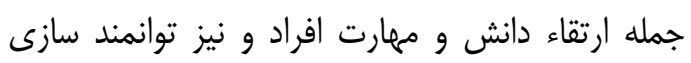
كروه هاى موثر بر رفتار افراد (اعضاى خانواده، كاركنان

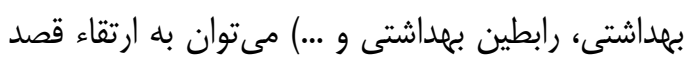

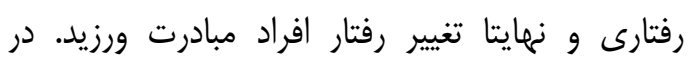
مطالعه اميرى و همكاران، عوامل قادر سازى مانند نبود مراكز تفريحى براى كذراندن اوقات فراغت، كران بوان بودن ماند مواد غذايى مفيد و نداشتن بضاعت مالى براى ندان انجام

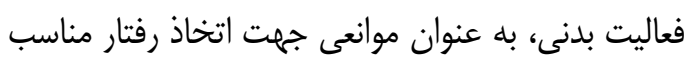

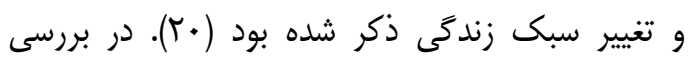
ارتباط بين سازه هاى مدل بزنف در اين مطالعه، بين هنجار هاى انتزاعى با عوامل قادر كننده، قصد رفتاري مداري

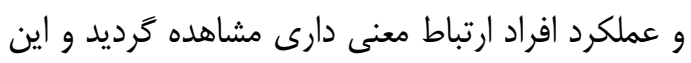

\section{بحث و نتيجه كيرى:}

يافته هاى اين بررسى نشان داد، در خصوص آبته آشنايى

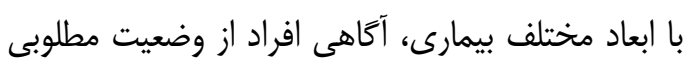

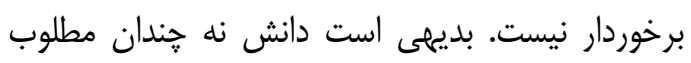

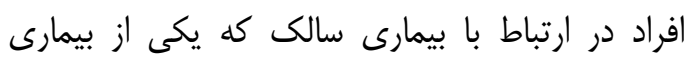

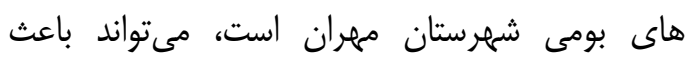

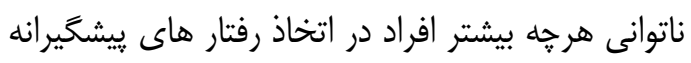

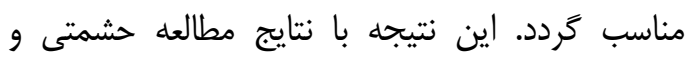

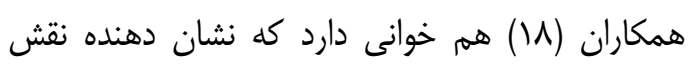

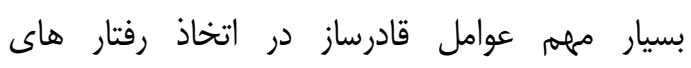

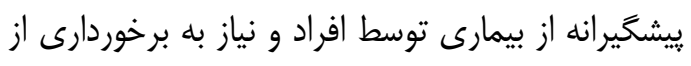
اطلاعات ضرورى و صحيح در مورد بيمارى به عنوان اساسى ترين كام براى اقدام به رفتار مناسب است.

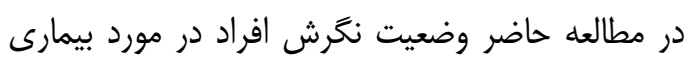

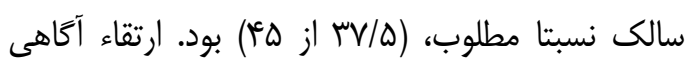

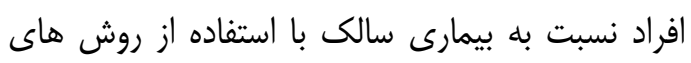

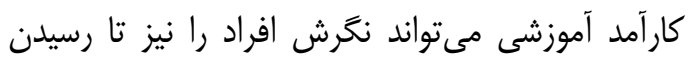

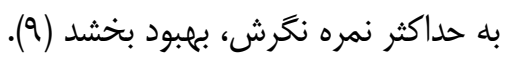

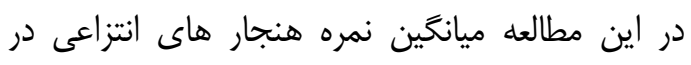

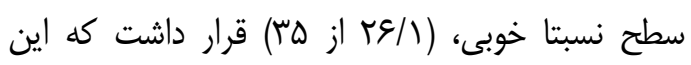

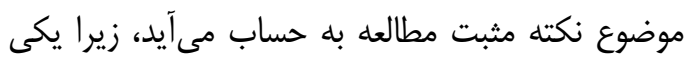

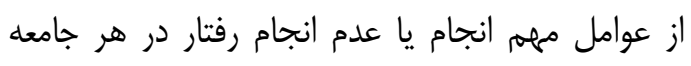

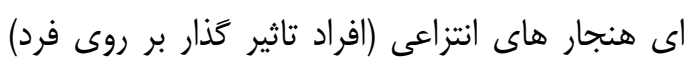

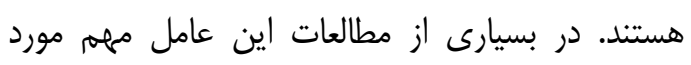

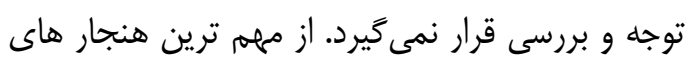

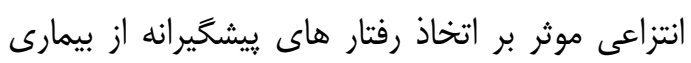


هم هنين بايد به افراد در خصوص معرفى مراكزى كه

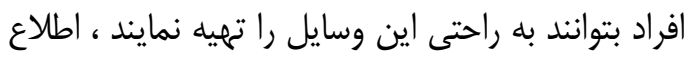
رسانى شود. از محدوديت هاى مطالعه مىتوان به جامعه آمارى كم

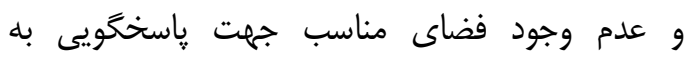

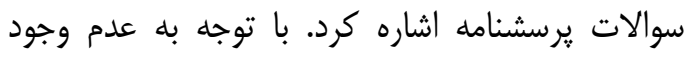

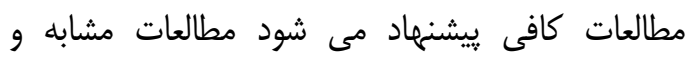
مكمل بيشترى در نقاط آندميك اين بيمارى در كشور

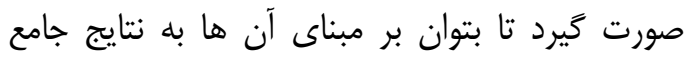

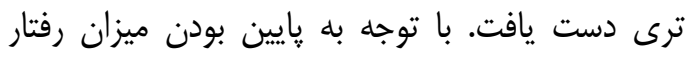

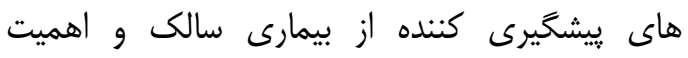
سازههاى هنجار هاى انتزاعى و عوامل قادرساز مىتوان

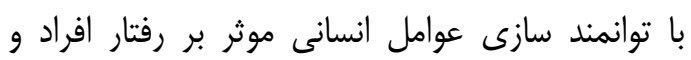

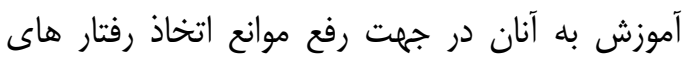

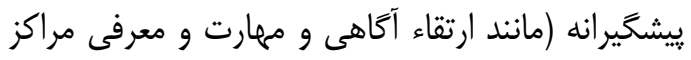
عرضه وسايل ييشخيرانه و استفاده از وسايل جايخزين) به بيشخيرى از اين بيمارى كمى كرد.

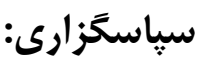

بدينوسيله از كاركنان محترم حوزه معاونت يزوهشى إنى

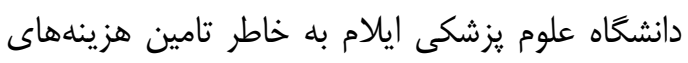

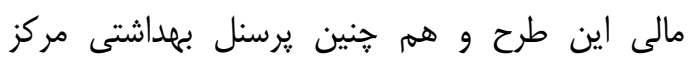

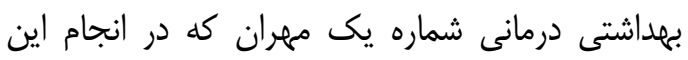
طرح همكارى داشتند، قدردانى به عمل آيد.

\section{References}

1. Sharafi M, Pezeshki B, Reisi A, Kalantari M, Naghizadeh MM, Dastmanesh S. [Detection of cutaneous leishmaniasis by PCR in Fasa district]. J Fasa Uni Med Sci 2013;3:266-70. (Persian)

2. Motamedi N, Hejazi S. H, Hazavei SMM, Zamani AR, Saberi S, Rahimi E. [Effect of education based on Health Belief Model on promoting preventive behavior of Cutaneous Leishmaniasis]. J Mil Med 2010;11:231-6. (Persian)

3. VahabiA, RassiY, Oshaghi MA, Vahabi B, Rafizadeh S, Sayyad S. [First survey on knowledge, attitude and practice about
بدين معناست كه همراهى و حمايت افراد درجه يك خانواده، همكاران، كاركنان بهداشتى، رابطين بهداشتى و... مى تواند در تقويت عوامل قادركننده از جمله ارتقاء بهاء ميزان آكاهى افراد در خصوص بيماند نقارى سالك، ايجاد

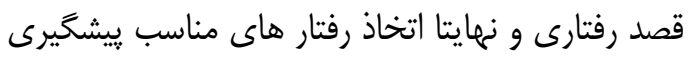
كننده از بيمارى سالك تاثيركذار باشد. اين نتيجه باريا مطالعه حسينى و همكاران هم خوانى دارد (Iالن) حشمتى و همكاران هم در مطالعه خود ارتباط قوى بين قصد رفتارى و رفتار را گزارش كرده اند (9).

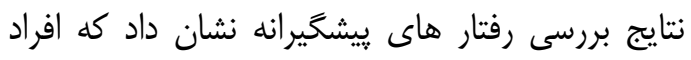

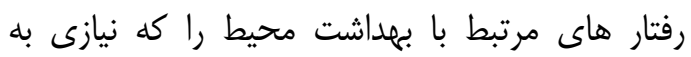

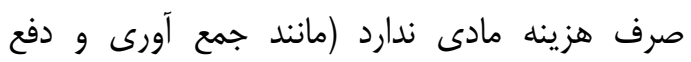
مناسب زباله)، در حد مطلوب انجام مى مدهند؛ اما ساير

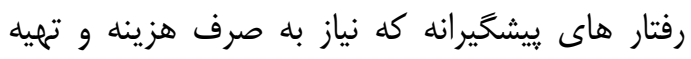
وسايل بيشخيرانه است؛ از جمله استفاده از يشه بنه بند،

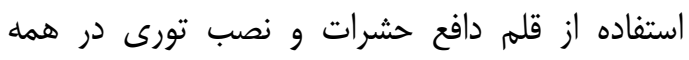

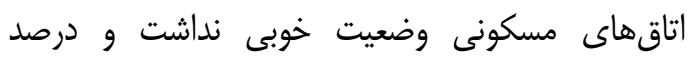

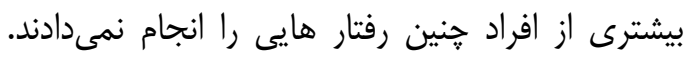

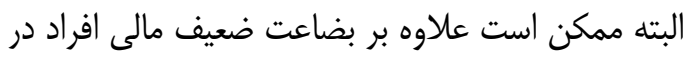

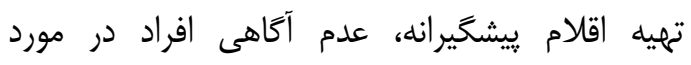

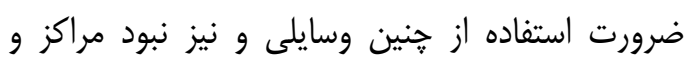
فروشگاه هاى عرضه اين وسايل، دليل عدم اتخاذ اين ونان

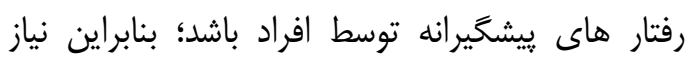

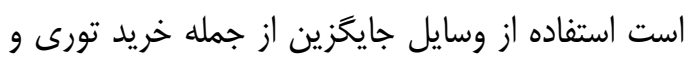

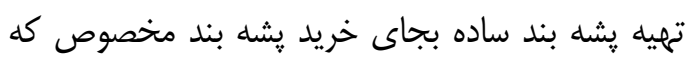

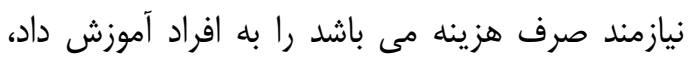

Cutaneous Leishmaniasis among dwellers of Musian district, Dehloran County, Southwestern of Iran]. Life Sc J 2013;10:864-8. (Persian)

4. Tilahun F, Alemu W, Mulatu G. Magnitude and associated factors of cutaneous leishmaniasis in Mekelle city Ayder referral hospital Tigray Northern Ethiopia. Clin Med Res 2014;3189-99.

5. Rahaei Z, Heshmati H, Hazavehei MM, Hasanzadeh A. [Relationship between educational practice of volunteer health workers and preventive behavior of households under their coverage regarding 
cutaneous leishmaniasis based on the BASNEF in Yazd city Iran]. SJSPH 2011;9:77-85. (Persian)

6. Mohammadiazni S, Nokandeh Z, Khorsandi AA, Saneidehkordi AR. [Epidemiology of cutaneous leishmaniasis in Damghan district]. Iranian $\mathbf{J}$ Mil Med 2010;12:131-5. (Persian)

7. Khajedaluee A, Yazdanpanah MJ, Seyed Nozadi SM, Fata A, Juya MR, Masoudi MH, et al. [Epidemiology of cutaneous leishmaniasis in Razavi Khorasan in 2011]. Med J Mashad Uni Med Sci 2014;57::647-54. (Persian)

8. Hosseini SH, Rajabzadeh R, Jajarmi H, Azarmi K, Sarposhi D, Ahmadpour M, et al. [The effect of educational program based on BASNEF model on volunteer health workers on preventive behaviors among families under supported of VHWs]. J North Khorasan Uni Med Sci 2015;7: 561-72. (Persian)

9. Heshmati H, Charkazi A, Hazavehei SMM, Rahaei Z, Dehnadi A. [Factors related to cutaneous leishmaniasis preventive behaviors on the basis of BASNEF model in residents of endemic area in Yazd Iran]. J Health Sys Res 2012;7:926-34. (Persian)

10.Kassi M, Kasi PM, Marri SM, Tareen I, Khawar T. Vector control in cutaneous leishmaniasis of the old world a review of literature. Dermatol Online J 2008; 14:1.

11. Saberi S, Zamani AR, Moatamedi N, Nilforoushzadeh MA, Jaffary F, Rahimi E, et al. [Evaluation of students knowledge, attitude and practice in relation to preventive strategies against Leishmaniasis in the hyperendemic region of Shahid Babaie airbase]. J Isfahan Med Sch 2012;29:2962-70. (Persian)

12. Hubley J. Understanding behaviour the key to successful health education. Trop Doc1988;18:1348.

13.Izadirad H, Masoudi GHR, Zareban I. [Evaluation of efficacy of education program based on BASNEF model on Self-care behaviors of women with hypertension]. Zahedan J Res Med Sci 2014;6:42-51. (Persian)

14. Baghianimoghadam MH, Rahaee Z, Morovatisharifabad MA, Sharifirad GH, Andishmand A, Azadbakht L. [Effects of education on self- monitoring of blood pressure based on BASNAF model in hypertensive patients]. JRMS 2010;15:70-7. (Persian)

15. Hazavehei SMM, Pirzadeh A, Entezari MH, Hasanzadeh A. [The effect of educational program based on BASNEF model on the nutritional behavior of students]. Zahedan J Res Med Sci 2010; 13:23-9. (Persian)

16. Kashfi SM, Jeihooni AK, Rezaianzadeh A. [Effect of health workers' training programs on preventive behaviour of Leishmaniasis based on BASNEF model]. JRHS 2012;12:114-8. (Persian)

17. Hazavehei MM, Heshmati H, Hasanzadeh A, Pourmazar A, Maghsoodlou D. [The effect of volunteer health workers educational program on the basis of BASNEF model on promotion of their practices about cutaneous leishmaniasis]. Zahedan J Res Med Sci 2014;16:16-21. (Persian)

18. Heshmati H, Rahaei Z, Hazavehei SMM, Dehnadi A, Hasanzadeh A. [Related factors to educational behaviors of health volunteers about cutaneous leishmaniasis on the basis of BASNEF model in Yazd]. J Ardabil Uni Med Sci 2011;1:48-56. (Persian)

19. Khanijeihooni A, Hatami M, Kashfi SM, Heshmati H. [The effectiveness of education based on BASNEF model program in promotion of preventive behavior of Leishmaniasis among health workers and families under health centers coverage]. J Fasa Uni Med Sci 2012;2:26-33. (Persian)

20. Amiri A, Rkhshany F, Farmanbar R. [The effect of educational 
program based on BASNEF model on healthy lifestyle of taxi drivers in Langroud]. J Torbat Heydariyeh Uni Med Sci 2014;1:45-54. (Persian)

21.Hosseini SH, Jajarmi H, Rajabzadeh R, Marzi Z, Arzamani K, Heshmati H. [The effect of educational program based on BASNEF model on promoting educational practice of volunteer health workers regarding to cutaneous leishmaniasis]. Sci Med J Ahwaz Jundishapur Uni Med Sci 2016;6:245-52.

(Persian) 22. 


\title{
Assessing preventive Behaviors of Leishmaniasis in Mehran County at 2014: Application of BASNEF Model
}

\author{
Jafarpour $M^{l}$, Aivazi $A^{l}$, Jalali $A^{l}$, Ghazanfari $Z^{1,2 *}$
}

(Received: February 10, 2016 Accepted: July 10, 2016)

\begin{abstract}
Introduction: Leishmaniasis is endemic in 88 countries and 350 million people in world are at risk. This study was developed, conducted, and evaluated to describe and analyze the preventive behaviors of people in the endemic area of Mehran County.

Materials \& methods: In this study, 92 people having $18^{+}$years living in Mehran Township and referred to health care center No. 1 of Mehran town in 2014 were selected through convenience sampling method. Data gathering was done using a researcher-made questionnaire, which was on the basis of BASNEF model, and its reliability and validity was verified. The completed questionnaires were encoded; their data were entered into SPSS software and analyzed by chi-square, independent $t$ test and Pearson correlation coefficient.
\end{abstract}

Findings: The relationship between age, gender, marital status, education level, family income, family history of leishmaniasis, and the preventive behaviors of the respondents toward the disease were examined and no significant statistical relationship was found $(\mathrm{P}>0.05)$. The results of this study illustrated the importance of subjective norms in this regard. The relationship between subjective norms and variables as enabling factors $(\mathrm{r}=0.262, \quad \mathrm{P}<0.05), \quad$ behavioral intention $(r=0.282, \mathrm{P}<0.01)$, and individual behavior $(\mathrm{r}=0.216, \mathrm{P}<0.05)$ was statistically significant.

Discussion \& conclusions: The most prevalent of suitable preventive behavior was relevant to remove the solid wastes in a proper way (91.3\%) and least prevalence was relevant to using the mosquito nets while sleeping $(5 / 4 \%)$.

Keywords: Leishmaniasis, Preventive behaviors, Health education, BASNEF Model

1. Dept of Public Health, Faculty of Health, Ilam University of Medical Sciences, Ilam, Iran

2. Psychosocial Injuries Research Center, Ilam University of Medical Sciences, Ilam, Iran

* Corresponding author Email: ghazanfari-z@ medilam.ac.ir

$\underline{\text { Scientific Journal of Ilam University of Medical Sciences }}$ 